\title{
Percepção de Moradores de uma Cidade Sede sobre a Copa do Mundo de Futebol 2014
}

\author{
Tadeu Mattos Farias \\ Fernanda Fernandes Gurgel \\ Raquel Farias Diniz \\ Universidade Federal do Rio Grande do Norte \\ Natal, RN, Brasil
}

\begin{abstract}
RESUMO
A Copa do Mundo de Futebol 2014, realizada no Brasil, provocou expectativa sobre o resultado final, principalmente pelos impactos gerados durante sua preparação. $\mathrm{O}$ objetivo desta pesquisa foi investigar a percepção ambiental dos moradores da cidade do Natal/RN acerca das mudanças decorrentes da realização do megaevento. Responderam voluntariamente o questionário 214 residentes de diferentes áreas da Região Metropolitana. A média de idade entre os participantes foi de 35 anos. 53\% dos participantes era do sexo masculino e a maioria tinha grau de instrução entre médio e superior. De forma geral, os participantes avaliaram mais positivamente as mudanças na cidade durante a realização do evento do que após o término. As áreas de turismo, emprego e imagem da cidade (propaganda) foram as mais bem avaliadas. Trânsito apresentou as menores avaliações nos dois momentos. Conclui-se que os participantes não acreditam em melhorias obtidas com a realização do evento.
\end{abstract}

Palavras-chave: Psicologia Ambiental; Percepção social; Ambiente urbano; Copa do mundo de futebol 2014.

\section{ABSTRACT}

\section{Residents' Perception of a Host City about the 2014 Football World Cup}

The 2014 football world cup, in Brazil, aroused expectations about the final result, particularly about its impacts generated during its preparation. The objective of this research was to investigate the citizens' environmental perception, in the city of Natal/RN, about the changes caused by the mega-event. The questionnaire was responded voluntarily by 214 residents of different areas of the Metropolitan Region. The age mean among participants was 35 years old. $53 \%$ of participants were male and the majority had degree of instruction between high school and graduated. Participants evaluated more positively the changes in the city during the event than after its ending. The areas of tourism, employment and the image of the city (advertising) were better evaluated. Traffic presented the lower evaluations in both moments. It can be concluded that participants do not believe in improvement obtained with the event.

Keywords: Environmental Psychology; Social perception; Urban environment; 2014 Football World Cup.

\section{RESUMEN}

\section{Percepción de los Residentes de una Ciudad Anfitriona del Mundial de Fútbol 2014}

La Copa Mundial de Fútbol 2014, celebrada en Brasil, provocó expectativas sobre el resultado final, sobretodo por los efectos generados durante su preparación. El objetivo de este estudio fue investigar la percepción ambiental de los residentes de la ciudad de Natal/RN acerca de los cambios derivados de la realización del mega evento. Voluntariamente completaron el cuestionario 214 residentes de diferentes áreas de la Región Metropolitana. La edad media de los participantes fue de 35 años. 53\% de los participantes eran hombres y la mayoría tenía grado de instrucción entre la escuela secundaria y graduación. En general, los participantes evaluaron más positivamente los cambios en la ciudad durante el evento que después de su finalización. Las áreas de turismo, el empleo y la imagen de la ciudad (la propaganda) fueron mejor evaluados. Tránsito tuvo la calificación más baja en los dos momentos. Llegamos a la conclusión de que los participantes no creen que mejoras serán obtenidas con el evento.

Palabras clave: Psicología Ambiental; Percepción social; Ambiente urbano; Copa Mundial de Fútbol 2014. 


\section{INTRODUÇÃO}

A Copa do Mundo FIFA de Futebol é o nome oficial atribuído ao megaevento realizado a cada quatro anos pela Federation International Football Association (FIFA) em diversos países do mundo desde 1930 (http://pt.fifa.com/tournaments/archive/ worldcup/index.html. Acesso em 10, abril, 2014). O Brasil sediou a quarta edição do evento, que aconteceu no ano de 1950, e voltou a recebê-lo no ano de 2014, em sua vigésima edição. É definido como megaevento em função dos impactos ocasionados na economia, política, meios de comunicação, equipamentos hoteleiros, estrutura urbana, bem como nos elementos socioculturais da nação hospedeira e pela dimensão do público envolvido (Hall, 1992; Reis, Telles \& DaCosta, 2013).

A Copa do mundo de 2014, realizada no Brasil, chamou a atenção pelo alto investimento, especialmente no que diz respeito à construção dos novos estádios, pela tradição futebolística do país (Galeano, 2006), o que gerou grande expectativa sobre o resultado final da competição, mas também pelas controvérsias geradas em torno da preparação, iniciadas desde o momento do anúncio do Brasil como país sede, no ano de 2007. Apesar de uma divulgação massiva associando o futebol à identidade do brasileiro (Gonçalves, 2013), e um entusiasmo com o evento, não é difícil encontrar posições contrárias, seja nos meios de comunicação, na academia, nas diferentes esferas de governo e entre a sociedade em geral.

Além disso, os principais debates sobre o tema tratam enfaticamente do impacto econômico - positivamente em termos de comércio turístico durante e depois, e negativamente no sentido do valor investido -, e da perspectiva de ter deixado ou não um legado positivo para as cidades-sede (Aquino \& Ferrari, 2013; Domingues, Betarelli Júnior, \& Magalhães, 2011; Preuss, 2013). No âmbito dos profissionais que pensam a promoção e garantia dos direitos humanos, inúmeras contestações surgiram sobre as ações efetivadas para as obras, como remoção de populações de locais de interesse, destruição de patrimônios locais, "limpeza" urbana em ações prioritariamente policiais, dentre outras. Outro assunto que muito circulou tratou das obras de mobilidade urbana, um suposto legado que seria deixado pelo evento.

Ainda que as cidades-sede tenham características diferentes, houve semelhança acerca dos processos envolvidos na preparação para o megaevento. A centralidade do debate econômico apoiado no pretexto da identidade futebolística e as denúncias de vio- lações dos direitos humanos foram marcas desse período. Qualquer que seja o tema, o que estava em jogo eram as mudanças que ocorreriam ou não nas cidades e o impacto para a vida dos moradores. Por esse motivo, esta pesquisa buscou investigar a percepção ambiental dos moradores da cidade do Natal/RN, uma das doze cidades-sede, acerca das mudanças decorrentes da realização da Copa 2014, identificando as mudanças mais significantes para a comunidade nas categorias: segurança pública, aparência geral da cidade, serviços de saúde, transporte, emprego, turismo, lazer, limpeza urbana, imagem da cidade (propaganda) e trânsito.

\section{MEGAEVENTOS E SEUS IMPACTOS SOCIOAMBIENTAIS URBANOS}

As grandes cidades, tal como as conhecemos, são resultado de um processo histórico complexo de transformações que vão desde o redesenho de sua organização espacial até a função que cumprem na vida dos cidadãos que nela habitam. A dialética modo de vida urbano-espaço físico da cidade é mediada pelos mais diversos elementos econômicos, políticos, sociais que não param de se transformar na história.

Nos últimos anos vem sendo chamada a atenção para o crescimento da importância das cidades que encerram um número crescente de moradores e tornam o campo cada vez mais parte de um complexo que termina no abastecimento das cidades. Nesse sentido, temos nas grandes cidades do mundo, centros de organização econômica, mas também cultural de boa parte da população mundial. Na intensificação da globalização com a internet e com a ampliação da efetividade do mercado mundial, o modo de vida produzido nas grandes cidades é propagado ao longo de distâncias imensas. "Não se tratava, portanto, da perda de sua centralidade econômica, mas de sua re-significação no interior do sistema produtivo internacional. Essas metrópoles assim re-significadas se passou a chamar de cidade global" (Carvalho, 2000, p. 71).

Nesse processo de intensificação das trocas globais ampliou-se também o intercâmbio turístico, com as grandes cidades disputando o mercado no que diz respeito a oferecer experiências únicas de lazer, descanso, encontro com a natureza ou mesmo prazer. São as fantasy cities (Gastal, 2006), com grandes parques temáticos, redes de resorts, turismo ecológico, paisagens paradisíacas, diversão ininterrupta, que passam a diversificar os produtos oferecidos pelas cidades. Aquelas que atraíram a migração em busca de emprego desde seu ressurgimento na modernidade passaram também a atrair cada vez mais habitantes 
temporários em busca de consumir seus produtos e seus espaços físicos.

Assim, numa velocidade vertiginosa, as cidades ganham mais amplamente o caráter de cidade-mercadoria. Com as cidades brasileiras não é diferente:

Podemos observar em nossas cidades, com efeito, um novo ciclo de mercantilização que combina as conhecidas práticas de acumulação urbana baseada na ação do capital mercantil local com as novas práticas empreendidas por uma nova coalização de interesses urbanos na direção da sua transformação em mercadoria (commodity) (Ribeiro \& Junior, 2011, p. 12).

Se por um lado a cidade já se mercantiliza na distribuição dos recursos imobiliários, nos processos de valorização, desvalorização e ocupação do solo por meio do poder de compra, a globalização começa a demandar espaços que possam ser consumidos por diferentes pessoas por intervalos de tempo geralmente curtos ou médios, a partir da indústria turística. Nas cidades contemporâneas ambos os processos são implicados um no outro, sendo turismo e mercantilização do solo urbano processos que se retroalimentam (Harvey, 2008; Soares, 2013)

$\mathrm{O}$ oposto de tal processo entende o solo urbano e a forma de sua ocupação como dimensões fundamentais para a produção e reprodução da vida humana em suas dimensões material e simbólica. Assim, a cidade deveria ser entendida por sua função social e não por sua função de mercado. No caso brasileiro, o direito à cidade como riqueza social em contraposição a sua mercantilização busca sua efetivação por meio do Estatuto da Cidade (Brasil, 2001).

$\mathrm{Na}$ contramão do desenvolvimento urbano almejado pelas diretrizes do direito à cidade, a entrada em cena dos megaeventos acaba por promover a efetivação da cidade-mercadoria (Ivo \& Osório, 2011) em uma dimensão ainda mais intensa, reforçando centralidades já existentes. Como consta na abordagem dada oficialmente pela Confederação Nacional do Comércio de Bens, Serviços e Turismo (2011):

Os chamados 'megaeventos' não são grandiosos para o turismo pelo volume de investimentos ou recursos gerados; não, pelo número de pessoas envolvidas ou atraídas por eles. São ou serão grandiosos se forem capazes de nos levar a um ponto superior, um ponto que supere os limites atuais da atividade turística no Brasil. Uma superação que está além do número de pernoites ou de dólares gastos por turista (p. 6).
Dessa forma, os megaeventos tomam a mesma direção que o desenvolvimento turístico tem tomado do ponto de vista de projeto urbano. Aliam-se num processo de turistificação, entendido como algo que "combina a urbanização turística e a urbanização para o turismo (...) processo em que a cidade vai se constituindo como território que se realiza para e através do turismo" (Alverga \& Dimenstein, 2009, p. 281).

Pode-se dizer, então, que a atração de megaeventos, como a copa do mundo, é catalisadora de um processo urbano já em desenvolvimento, alimentado pela globalização dos espaços físicos, que tem como veículo o turismo mundial. Isso implica em transformações na configuração social, urbana e econômica das cidades que têm suas diretrizes no turismo globalizado.

\section{A POPULAÇÃO AFETADA PELOS IMPACTOS DO MEGAEVENTO EM NATAL/RN}

O estudo realizado com moradores de uma cidade sede justifica-se pelo fato das pesquisas sobre megaeventos geralmente estarem concentradas nos impactos econômicos gerados pela sua preparação e realização, bem como pela herança deixada por ele, negligenciando os aspectos subjetivos relativos ao fenômeno (Aquino \& Ferrari, 2013).

A pesquisa, realizada na Região Metropolitana de Natal/RN, priorizou conhecer a percepção de seus moradores, uma vez que seu cotidiano foi impactado durante o evento, e segue sofrendo os impactos por seus desdobramentos. Sendo assim, destaca-se a importância de dar voz a esta população, visto que, por estarem imersos na dinâmica da cidade (não só durante a realização dos jogos, mas durante todas as fases da transformação e após a realização do megaevento), tais pessoas estão plenamente aptas a opinar de forma contextualizada e eficiente sobre as mudanças vivenciadas, considerando que os megaeventos instituem novas formas de viver, de significar e de usar a cidade. Sem subestimar os impactos sofridos por diversos outros setores da sociedade (gestão municipal, estadual e federal, organizações de trabalho, patrocinadores do evento, turistas), enfocamos o fato de que as mudanças ocorridas transformam a relação das pessoas com seus entornos, nos vínculos estabelecidos e nas memórias associadas ao lugar, o que justifica a realização de estudos sobre os impactos socioambientais dessas ações e o modo como os habitantes da cidade os percebem e participam do processo de implantação/ consolidação das mudanças. 
Destaca-se, ainda, o precário processo participativo popular no debate sobre os elementos que delimitam o evento (Maranhão \& Pequeno, 2012), mesmo quando sua realização possibilita a discussão de questões que se tornam visíveis e urgentes na iminência da sua consumação. Em resumo, o evento é um catalisador de debates, embates e reflexões que provocam a população acerca de temas tão amplos quanto a necessidade de apropriar-se da cidade, ter direito a ela (Harvey, 2008). Assim, o conhecimento produzido pela pesquisa pretende dar visibilidade ao sentido dessa apropriação, da interpretação e da vivência popular frente ao evento, bem como a ressignificação de um ambiente que passa por inúmeras transformações (Moreno, 1999).

O referencial escolhido para o estudo tem base nos estudos das relações pessoa-ambiente, como tentativa de compreender como as pessoas influenciam e são influenciadas pelo ambiente sociofísico imediato, no caso da cidade na qual residem, visto que as cidades produzem "subjetividades, modos de pensar e reproduzir a continuidade e a permanência humana na história" (Castro, 2012, p. 76). Vale destacar que os resultados aqui apresentados fazem parte de um estudo preliminar para conhecer o tema, visto que está inserido em uma investigação mais ampla sobre aspectos psicológicos relacionados ao megaevento.

\section{PERCEPÇÃO AMBIENTAL E MUDANÇAS NA CIDADE}

A percepção ambiental é resultado da relação estabelecida entre a pessoa e o ambiente no qual está inserida, tendo como intermediários as experiências, os afetos e cognições, sendo importante para a apropriação e identificação dos lugares (Kuhnen, 2011). O modo como o espaço é apresentado ao seu observador, além de suas formas, influencia a percepção do ambiente. É válido ressaltar que dita percepção resulta de processos bidirecionais entre o observador e o meio, seja ele natural ou urbano (Lynch, 2009).

Os vínculos estabelecidos entre pessoas e seus ambientes são processos em constante transformação e, sendo mediados pelas experiências estabelecidas com o lugar, são sensíveis às transformações do mesmo. Sejam mudanças físicas, culturais ou das relações sociais locais, são acompanhadas por um processo de interpretação e assimilação por parte dos indivíduos, que re-significam o ambiente em função de seus referenciais afetivos e cognitivos e suas expectativas sobre as interações futuras. Devine-Wright e Howes (2010) propõem um esquema processual para a relação entre indivíduos e mudanças no local que se inicia com o conhecimento da mudança, a interpretação da mesma em função das implicações para o lugar, a avaliação dos possíveis resultados, e é organizada pelos indivíduos em respostas cognitivas ou até mesmo comportamentais como reivindicações contrárias à mudança etc.

O processo de mudança ambiental sofrido pelas cidades, impactadas pelo desenvolvimento urbano, ocasiona transformações também na forma como as pessoas se relacionam, percebem, significam e utilizam sua vizinhança e entornos menos contíguos. Isto porque as cidades são espaços sociais construídos historicamente, permeados por representações, memórias e utilidade (Tuan, 1983) e sua mutação implica em alterar a forma como as pessoas a percebem. Sendo assim a compreensão das "modificações efetuadas no local, de acordo com as necessidades de expansão e desenvolvimento urbano, bem como suas consequências para a vizinhança/comunidade, bem como sobre como esse processo pode afetar a percepção e a relação íntima com o lugar onde vivem" (César, 2013, p. 52).

A percepção ambiental e a incorporação das mudanças na cidade por parte dos indivíduos, assim, estão ligadas à forma como os moradores se apropriam do ambiente urbano. Daí que o modo como as mudanças se processam influencia os significados simbólicos, mas também a forma de viver a cidade nas atividades do dia-a-dia, uma vez que a dinâmica de apropriação passa por ambas as dimensões, simbólica e territorial (Vidal \& Pol, 2005). Os megaeventos com seus impactos e a assimilação e avaliação desses impactos pelos moradores dizem do modo como é compreendida e conduzida a vida nas cidades-sede.

\section{ESTRATÉGIA METODOLÓGICA}

A presente pesquisa tratou-se de um estudo de caráter exploratório com delineamento quantitativo (Corbeta, 2007) que objetivou explorar as percepções de moradores sobre aspectos relacionados com a realização do megaevento Copa do Mundo 2014 na cidade em que residem. Embora de corte horizontal, buscou apreender as percepções dos participantes sobre aspectos em longo prazo.

\section{Participantes}

Foi utilizado o método de amostragem por conveniência, tendo como critério de inclusão residir na Região Metropolitana (RM) da cidade do Natal (RN/Brasil) há pelo menos um ano. Participaram voluntariamente 214 residentes em diferentes áreas 
da RM. A média de idade entre os participantes foi de 35 anos ( $\mathrm{DP}=12,5) .53 \%$ dos participantes era do sexo masculino e a maioria tinha grau de instrução entre médio (47\%) e superior (37\%).

\section{Instrumento}

O questionário utilizado foi desenvolvido especificamente para a pesquisa, tendo sido composto por questões fechadas que mantinham relação com diferentes aspectos apontados pela literatura sobre os impactos sociais, econômicos, urbanos e ambientais de megaeventos. O instrumento foi submetido a testespiloto e adequação da linguagem para que pudesse ser respondido por pessoas com diferentes graus de instrução.

As questões foram divididas em três blocos, tendo o primeiro contemplado dados sociodemográficos (idade, sexo, grau de instrução), para delimitar o perfil dos participantes e serem utilizados em análises conjuntas com as demais variáveis do estudo. No segundo bloco, foram abordados os posicionamentos em relação à cidade do Natal, futebol (gostar ou não gostar) e sobre a realização da Copa do Mundo na cidade do Natal (ser contrário ou favorável a sua realização). Foram abordadas também as avaliações sobre as mudanças decorrentes do mundial - considerando tanto o momento durante sua realização, quanto o momento posterior ao término - nas áreas de segurança pública, aparência geral da cidade, serviços de saúde, transporte, emprego, turismo, lazer, limpeza urbana, imagem da cidade (propaganda) e trânsito (em escala Likert, variando de -2 muito negativo a +2 muito positivo). Por fim, o terceiro bloco contemplou questões relativas à autoavaliação sobre o quão informado o participante se considerava em relação ao megaevento em Natal (escala que variou de 0 - nada a 4 - muito informado) e os canais de informação utilizados.

\section{Procedimentos}

A coleta de dados foi realizada entre os meses de março e maio de 2013, momento em que as obras e modificações no entorno do estádio Arena das Dunas estavam sendo conduzidas. Os questionários foram aplicados de forma individual por quinze pesquisadores previamente treinados, e que se distribuíram em diferentes zonas da RM de Natal de forma a alcançar maior heterogeneidade no perfil dos participantes. Foi seguido um procedimento padrão, no qual os participantes foram abordados pelos pesquisadores, receberam informações sobre os objetivos e o contexto da pesquisa e foram convidados a participar voluntariamente. O tempo de aplicação médio foi de 20 minutos. Ressalta-se que foram tomados os cuidados éticos relativos à pesquisa científica com seres humanos, tendo sido feito o informe sobre a participação voluntária e assegurado o anonimato dos participantes (American Psychological Association, 2002).

\section{Análise dos dados}

Os dados foram digitalizados em formato de banco de dados e as análises foram conduzidas com auxílio do programa estatístico SPSS (Statistical Package for the Social Science), versão 21. Foram identificados os indicadores descritivos (frequência, média, desvio padrão), assim como foram exploradas as correlações por via de análises uni e bivariadas, utilizando-se testes não-paramétricos, visto que os dados não atenderam ao critério de normalidade.

\section{RESULTADOS E DISCUSSÃO}

A maioria dos participantes afirmou ser favorável à realização da Copa em Natal (54\%), posicionamento que não variou em função de variáveis sociodemográficas como sexo e idade dos participantes, algo inesperado a ser mais bem explorado em etapas posteriores da investigação. Observou-se que afetos positivos relacionados à cidade e ao esporte (gostar de Natal e gostar de futebol) apresentaram correlações positivas com o posicionamento favorável $(p<0,05)$. Observou-se, também, associações entre o posicionamento e o grau de instrução, tendo os participantes com nível superior apresentado maior rejeição ao evento, quando comparados aos grupos com níveis educacionais médio e fundamental $(\mathrm{p}<0,04)$. É possível que este fato esteja relacionado a uma forma de vínculo aos lugares de tipo ideológico (Lewicka, 2011), que sofre influência dos processos de aquisição de informação, capital cultural, e posicionamento mais do que de experiências pessoais permanentes no local.

\section{Percepção de mudanças}

De forma geral, os participantes avaliaram mais positivamente as mudanças na cidade durante a realização do evento, do que após o término $(p<0,05)$, exceto em relação a trânsito, que teve avaliações negativas em ambos os momentos. Estes resultados indicam consonância com outros estudos que apontam um pessimismo temporal sobre questões ambientais percebidas ao longo do tempo (Gifford et al., 2009). Considerando o momento de realização do evento, as áreas de turismo, emprego e imagem da cidade 
(propaganda) foram as mais bem avaliadas, com médias entre 1,57 e 1,19 (escala de -2 a +2). As mudanças mais bem avaliadas considerando o momento após o término do evento foram também turismo e imagem, porém com médias notoriamente mais baixas, 0,56 e 0,45 respectivamente (Tabela 1 ).

\section{TABELA 1}

Médias (M) e desvios padrão (DP) das avaliações das mudanças antes e após a Copa 2014 pelo grupo total de respondentes

\begin{tabular}{lccccc}
\hline & \multicolumn{3}{c}{ Durante } & \multicolumn{3}{c}{ Após } & \multirow{2}{*}{$p$} \\
\cline { 2 - 5 } & $M$ & $D P$ & $M$ & $D P$ & \\
\hline Segurança pública & 0,58 & 1,17 & $-0,56$ & 1,09 & 0,00 \\
$\begin{array}{l}\text { Aparência geral da cidade } \\
\text { (estética) }\end{array}$ & 0,89 & 0,98 & 0,00 & 1,13 & 0,00 \\
Serviços de saúde & $-0,06$ & 1,30 & $-0,79$ & 1,11 & 0,00 \\
Serviços de transporte & 0,27 & 1,25 & $-0,39$ & 1,09 & 0,00 \\
Emprego & 1,19 & 0,96 & $-0,05$ & 1,11 & 0,00 \\
Turismo & 1,57 & 0,70 & 0,56 & 1,09 & 0,00 \\
Opções de lazer & 0,60 & 0,99 & 0,20 & 0,97 & 0,02 \\
Serviços de limpeza urbana & 0,77 & 1,04 & $-0,14$ & 1,10 & 0,00 \\
Imagem da cidade & 1,28 & 0,85 & 0,45 & 1,13 & 0,00 \\
(propaganda) & & & & & \\
Trânsito & $-0,54$ & 1,37 & $-0,46$ & 1,20 & 0,00 \\
\hline
\end{tabular}

O fato das médias, com exceção do trânsito, decrescerem quando comparados os resultados antes e após o evento manifesta a descrença dos participantes da pesquisa nas melhorias que serão obtidas com a realização do evento. $\mathrm{O}$ dito legado não parece ter sido apropriado pelos respondentes como algo positivo. Destaque deve ser dado aos maiores intervalos apresentados que se dão nos itens emprego, segurança pública e turismo (-1,24, -1,14 e-1,01, respectivamente). Emprego aparece como o item com maior impacto após a Copa em virtude dos trabalhos temporários gerados na construção do estádio e no setor turístico, o que é confirmado pelo item turismo que também tem um dos maiores decréscimos. O item segurança pública é percebido como algo que também sofrerá impacto em função das próprias estratégias de organização do evento e estruturação para o fluxo turístico do período.

A exceção é o item trânsito que já apresenta a média mais baixa antes e se eleva ligeiramente após o evento. Algo que poderia ser atribuído à confiança dos moradores no fato de a mobilidade ser um dos legados deixados pela Copa, mas que até o momento da coleta dos dados era algo inexistente em função das diversas obras realizadas na cidade que dificultavam mover-se por ela. Vale ressaltar que as médias inferiores podem ser reflexo do fenômeno contemporâneo de crescimento do trânsito nas cidades, com falta de estrutura para transportes coletivos e o aumento do uso do transporte individual, que gera sobrecarga e ocasiona estresse nos moradores das urbes, tornando-se um problema de saúde coletiva (Cristo, 2013).

As avaliações sobre as mudanças variaram significativamente em todas as áreas (exceto aparência da cidade), em ambos os momentos, quando associadas ao posicionamento dos participantes $(p \leq 0,01)$. Nesse sentido, os participantes favoráveis à realização do megaevento avaliaram de forma mais positiva as mudanças na cidade, assim como os participantes contrários avaliaram de forma mais negativa (Tabela 2).

TABELA 2

Avaliações das mudanças considerando posicionamento (médias, desvios padrão e significância)

\begin{tabular}{lccccc}
\hline & \multicolumn{4}{c}{ A favor } & \multicolumn{2}{c}{ Contra } & \\
\cline { 2 - 5 } & $M$ & $D P$ & $M$ & $D P$ & \\
\hline Durante o evento & & & & & \\
Segurança pública & 0,82 & 1,10 & 0,27 & 1,19 & 0,00 \\
Serviços de saúde & 0,12 & 1,32 & $-0,29$ & 1,26 & 0,01 \\
Serviços de transporte & 0,52 & 1,20 & $-0,05$ & 1,26 & 0,00 \\
Emprego & 1,32 & 0,97 & 1,03 & 0,94 & 0,00 \\
Turismo & 1,67 & 0,62 & 1,43 & 0,77 & 0,00 \\
Opções de lazer & 0,75 & 0,96 & 0,41 & 1,005 & 0,01 \\
Serviços de limpeza urbana & 0,87 & 1,04 & 0,63 & 1,05 & 0,00 \\
Imagem da cidade & 1,45 & 0,78 & 1,06 & 0,90 & 0,00 \\
(propaganda) & & & & & \\
Trânsito & $-0,30$ & 1,42 & $-0,84$ & 1,27 & 0,00 \\
Após o evento & & & & & \\
Segurança pública & $-0,24$ & 1,15 & $-0,94$ & 0,88 & 0,00 \\
Serviços de saúde & $-0,50$ & 1,19 & $-1,15$ & 0,89 & 0,00 \\
Serviços de transporte & 0,02 & 0,99 & $-0,91$ & 0,99 & 0,00 \\
Emprego & 0,15 & 1,14 & $-0,32$ & 1,03 & 0,00 \\
Turismo & 0,79 & 1,07 & 0,25 & 1,04 & 0,00 \\
Opções de lazer & 0,45 & 0,93 & $-0,10$ & 0,95 & 0,00 \\
Serviços de limpeza urbanan & 0,09 & 1,11 & $-0,44$ & 1,03 & 0,00 \\
Imagem da cidade & 0,77 & 1,12 & 0,04 & 1,02 & 0,00 \\
(propaganda) & & & & & \\
Trânsito & $-0,20$ & 1,17 & $-1,77$ & 1,17 & 0,00 \\
\hline
\end{tabular}

A avaliação das mudanças em alguns setores também divergiu quando considerado o grau de instrução dos participantes, porém apenas em relação ao momento de realização o evento. Não houve 
diferenças entre os grupos nas avaliações das mudanças após, com exceção de trânsito que recebeu avaliações negativas tanto antes como após o evento. Constatou-se que, quanto menor o grau de instrução, maiores as médias atribuídas na avaliação das mudanças. Como visto anteriormente, é um ponto de convergência com o posicionamento dos participantes, mantendo relação com a possível influência dos processos de aquisição de informação e capital cultural (Lewicka, 2011). Os setores que apresentaram diferenças significativas entre os grupos foram segurança pública, saúde, transporte e emprego (Tabela 3).

TABELA 3

Avaliações das mudanças considerando grau de instrução (médias, desvios padrão e significância)

\begin{tabular}{|c|c|c|c|c|c|c|c|}
\hline & \multicolumn{2}{|c|}{ Fundamental } & \multicolumn{2}{|c|}{ Médio } & \multicolumn{2}{|c|}{ Superior } & \multirow{2}{*}{$p$} \\
\hline & $M$ & $D P$ & $M$ & $D P$ & $M$ & $D P$ & \\
\hline \multicolumn{8}{|c|}{ Durante o evento } \\
\hline $\begin{array}{l}\text { Segurança } \\
\text { pública }\end{array}$ & 0,91 & 1,17 & 0,62 & 1,18 & 0,37 & 1,12 & 0,02 \\
\hline $\begin{array}{l}\text { Serviços de } \\
\text { saúde }\end{array}$ & 0,34 & 1,38 & 0,12 & 1,25 & $-0,48$ & 1,23 & 0,00 \\
\hline $\begin{array}{l}\text { Serviços de } \\
\text { transporte }\end{array}$ & 0,84 & 1,24 & 0,30 & 1,20 & $-0,05$ & 1,24 & 0,00 \\
\hline Emprego & 1,63 & 0,83 & 1,11 & 1,00 & 1,13 & 0,93 & 0,00 \\
\hline Trânsito & 0,00 & 1,61 & $-0,46$ & 1,31 & $-0,89$ & 1,23 & 0,00 \\
\hline \multicolumn{8}{|l|}{ Após o evento } \\
\hline Trânsito & $-0,16$ & 1,41 & $-0,36$ & 1,15 & $-0,71$ & 1,09 & 0,04 \\
\hline
\end{tabular}

Quanto à autoavaliação sobre o quão informados sobre o megaevento os participantes se consideravam, em relação ao grupo total a média foi de 2,19 (numa escala de 4 pontos; $\mathrm{DP}=1,08)$. Em relação aos veículos de informação sobre a Copa em Natal, 83\% afirmou usar a televisão, seguido de internet $47 \%$, familiares/ amigos 38\% e jornais/revistas impressas $31 \%$.

Observou-se que, dentre os participantes que afirmaram acessar a internet, a maioria foi contrária à realização do megaevento na cidade $(p=0,02)$. A internet foi o único veículo de informação que apresentou associação com o posicionamento dos participantes, sendo os usuários significativamente mais jovens $(M=30$ anos, $\mathrm{DP}=8,79)$ do que os não usuários $(\mathrm{M}=39$ anos; $\mathrm{DP}=13,86)$. Os usuários de internet também avaliaram mais negativamente as mudanças nos setores de transporte durante a Copa e de saúde após o evento. Considerando que a internet possibilita o acesso a diversas fontes de informação, por vezes contraditórias, pode fomentar posicionamentos críticos em relação ao evento. Um fato a ser ressaltado é o fato de que o acesso à internet, em nossa realidade social, está vinculado ao poder aquisitivo (IBGE, 2013), o que converge com os dados referentes a outro fator associado, o nível de instrução.

\section{CONCLUSÕES}

A relevância da pesquisa aqui apresentada está ancorada na necessidade de dar voz à população que tem seu cotidiano afetado pelos eventos que antecederam, acompanharam e sucedem a realização da Copa do mundo de futebol 2014 na cidade do Natal. Considerando, desse modo, que evento não está circunscrito ao lugar onde os jogos acontecerão, nem ao tempo destinado a ocorrência das partidas. Os impactos estendem-se temporal e espacialmente pela cidade, causando diversos câmbios na vida urbana.

É válido salientar que os achados da presente investigação já vem sendo foco de aprofundamento em desdobramentos da investigação sobre os significados psicológicos atribuídos ao megaevento na cidade do Natal. Dentre esses achados estão as associações entre as percepções sobre o evento e grau de instrução dos respondentes (os de maior nível de instrução são mais desfavoráveis a realização da Copa), bem como entre as percepções sobre o evento e os tipos de canais/ veículos usados para acessar a informação. Sobre o acesso a internet e a associação com o posicionamento contrário à Copa em Natal, abre-se espaço para discussões acerca do papel da mídia online sobre as percepções acerca do megaevento. Destacamos também a avaliação positiva das dimensões de turismo, emprego e imagem da cidade (propaganda), algo que notavelmente converge com o discurso midiático, no qual o legado é algo temporário e restrito a campos específicos. Ainda assim, é importante salientar que a cidade em questão já possui uma relação forte com o turismo que, além de movimentar a economia local, está presente no imaginário social dos seus moradores. Ressaltando ainda que, com exceção de trânsito, todos os indicadores apresentaram decréscimo no período após Copa, apontando um pessimismo da população sobre a herança do evento. Todos esses aspectos serão mais bem explorados em desdobramentos da investigação.

Sobre as estratégias metodológicas adotadas, avaliamos que o uso do questionário mostrou-se satisfatório no estudo da percepção das mudanças socioambientais causadas no meio urbano pela Copa 2014. Como sugestão para futuras pesquisas há a possibilidade de ampliar a coleta para outras cidades no pós-copa com o objetivo de comparar as diversas realidades que marcam a complexidade cultural do 
país, e ainda de comparar a percepção da população natalense antes e após a realização do megaevento, o que caraterizaria um avanço na percpetiva longitudinal do estudo. Outros fenômenos também podem ser estudados, buscando conhecer o conteúdo das crenças construídas sobre o megaevento na cidade, ou mesmo tentando conhecer como e se a mídia interfere nos processos de aceitação e/ou rechaço ao evento.

\section{REFERÊNCIAS}

Alverga, A. \& Dimenstein, M. (2009). Turismo e consumo dos cidades: apontamentos sobre o biopoder. Mal-estar e subjetividade, 9(1), 277-311.

Aquino, F. \& Ferrari, C. M. (2013). Gol de quem? A comunicação e o turismo na Copa do Mundo Brasil 2014. Revista Hospitalidade, 1(1), 97-120.

American Psychological Association. (2002). Ethical principles of psychologists and code of conduct. American Psychologist, 57(12), 1060-1073. http://dx.doi.org/10.1037/0003-066X.57.12.1060

Carvalho, M. (2000). Cidade Global: anotações críticas sobre um conceito. São Paulo em Perspectiva, 14(4), 70-82. http://dx.doi.org/10.1590/S0102-88392000000400008

Castro, E. A. S. (2012). Segregação socioespacial, constituição do sujeito e significação do cotidiano. Psicologia \& Sociedade, 24(1), 75-83. http://dx.doi.org/10.1590/S0102-71822012000100009

César, J. A. G. A. (2013). Modificações no ambiente sócio-físico entre 2005 e 2011: a percepção dos moradores de Itapuama, Cabo de Santo Agostinho/Pernambuco (Dissertação de Mestrado não publicada). Universidade Federal do Rio Grande do Norte (UFRN), Natal/RN.

Confederação Nacional do Comércio de Bens, Serviços e Turismo. (2011). Infraestrutura turística e megaeventos. Rio de Janeiro.

Corbetta, P. (2007). Metodología y técnicas de investigación social. Madri: McGraw.

Devine-Wright, P. \& Howes, Y. (2010). Disruption to place attachment and the protection of restorative environments: A wind energy case study. Journal of environmental Psychology, 30(3), 271-280. http://dx.doi.org/10.1016/j. jenvp.2010.01.008

Cristo, F. (2013). O hábito de usar automóvel tem relação com o transporte coletivo ruim? (Tese de Doutorado não publicada). Universidade de Brasília (UnB), Brasília/DF.

Domingues, E. P., Betarelli Junior, A. A., \& Magalhães, A. S. (2011). Quanto Vale o Show? Impactos Econômicos dos Investimentos da Copa do Mundo 2014 no Brasil. Estudos Econômicos, 41(2), 409-439. http://dx.doi.org/10.1590/ S0101-41612011000200008

Galeano, E. (2006). El fútbol a sol y sombra. Madrid: Siglo XXI.

Gastal, S. (2006). Alegorias urbanas: o passado como subterfúgio. Campinas: Papirus.

Gonçalves, G. R. (2013). A lógica do "elefante branco": obsolescência programada do espaço na Copa de 2014. Ateliê Geográfico, 7(3), 240-256.

Gifford, R., Scannell, L., Kormos. C., Smolova, L., Biel. A., Boncu, S., Uzzell, D. et al. (2009). Temporal pessimism and spatial optimism in environmental assessments: An 18-nation study. Journal of Environmental Psychology, 19(1), 1-12. http://dx.doi.org/10.1016/j.jenvp.2008.06.001

Hall, C. M. (1992). Hallmark Tourist Events: Impacts, management and planning. London: Belhaven Press.

Harvey, D. (2008). El Derecho a la ciudad. New Left Review, 53, 23-40.

Instituto Brasileiro de Geografia e Estatística- IBGE. (2013). Acesso à Internet e posse de telefone móvel celular para uso pessoal 2011. Brasília, DF: Ministério do Planejamento, Orçamento e Gestão.

Ivo, A. B. L. \& Brito, G. A. (2011). "Una nueva copa en un nuevo país” Intervenciones urbanas y creación de ciudades para el Mundial de Fútbol Brasil 2014. Revista Bitácora Urbano Territorial, 18(1), 39-54, 2011.

Kuhnen, A. (2011). Percepção Ambiental. In S. Cavalcante, G. A Elali. (Orgs.). Temas básicos em psicologia ambiental (pp. 250-266). Petrópolis: Vozes.

Lewicka, M. (2011). On the variants of people's relationships with places: Hummon's typology revisited. Environment and Behavior, 43(5), 676-709. http://dx.doi.org/10.1177/0013916510364917

Lynch, K. (2009). A imagem da cidade. Lisboa: Edições 70.

Maranhão, C. H. S. \& Pequeno, E. A. (2012). Uma análise da participação popular no projeto Natal Copa 2014. Turismo: Estudos \& práticas, 1(1), 05-26.

Moreno, A. (1999). El significado psicológico de conceptos relativos a la educación ambiental. Revista Interamericana de Educación de Adultos, 1, 93-114.

Preuss, H. (2013). The contribution of the FIFA World Cup and the Olympic Games to Green Economy. Sustainability, 5, 3581-3600. http://dx.doi.org/10.3390/su5083581 
Ribeiro, L. C., \& Junior, O. (2011). Desafios da questão urbana na perspectiva do direito à Cidade. In O. Junior, A. C. Christovão, \& P. Novaes (Orgs.). Políticas públicas e direito à cidade: programa interdisciplinar de formação de agentes sociais e conselheiros municipais (pp. 11-16). Rio de Janeiro: Letra Capital.

Reis, R. M., Telles, S. C. C., \& Da Costa L. P. (2013). Estádios da copa de 2014: perspectivas de um legado. Pensar a Prática, 16(2), 320-618. http://dx.doi.org/10.5216/rpp.v16i2.17712

Soares, P. R. R. (2013). Megaeventos esportivos e o urbano: a copa do mundo de 2014 e seus impactos nas cidades brasileiras. Revista FSA, 10(4), 195-214. http://dx.doi.org/10.12819/2013.10.4.11

Tuan, Y. (1983). Espaço e lugar: a perspectiva da experiência. São Paulo: DIFEL.

Vidal, T. \& Pol, E. (2005). La apropiación del espacio: uma propuesta teórica para comprender la vinculación entre las personas y los lugares. Anuario de Psicologia, 36(3), 281-297.

Autores:

TAdEU MatTos Farias - Doutorando, Universidade Federal do Rio Grande do Norte.

FERNANDA FERNANDES GURGEL - Doutora, Universidade Federal do Rio Grande do Norte.

RAQUEL FARIAS DINIZ - Doutora, Universidade Federal do Rio Grande do Norte.

Endereço para correspondência:

Tadeu Mattos Farias

Rua Petra Kelly, 706 - Bloco Pirangi, apto. 302 - Nova Parnamirim

CEP 59 152-330 Parnamirim, RN, Brasil

E-mail: <tadeumattos1@gmail.com>

Recebido em: 20.05.14

Aceito em: 24.11.14 